\title{
Diphenoxylate Hydrochloride/Atropine Sulfate
}

National Cancer Institute

\section{Source}

National Cancer Institute. Diphenoxylate Hydrochloride/Atropine Sulfate. NCI Thesaurus.

Code C135189.

A formulation containing the hydrochloride salt form of diphenoxylate, a synthetic opioid of the phenylpiperidine class, and the sulfate salt form of the anticholinergic agent atropine, with antidiarrheal activity. Upon oral administration, diphenoxylate acts on opioid receptors in the gastrointestinal (GI) tract, thereby decreasing GI motility, prolong ing transit time, and preventing diarrhea. Through its anticholinergic effects, atropine prevents deliberate over-usage of diphenoxylate by triggering very unpleasant side effects (SEs), such as severe weakness and nausea. 